Ian R. Thomson MD, Robert J. Hudson MD, Morley Rosenbloom Bsc (Hon), Robert C. Meatherall PH D

\title{
A randomized double- blind comparison of fentanyl and sufentanil anaesthesia for coronary artery surgery
}

\begin{abstract}
Using a randomized double-blind protocol the authors compared two rarcotic anaesthetic regimens in 33 palients with good ventricular function undergoing coronary artery surgery. After premedication with morphine and scopolamine, patients received either fentanyl $100 \mu \mathrm{g} \cdot \mathrm{kg}^{-1}(n=16)$, or sufentanil $15 \mu \mathrm{g} \cdot \mathrm{kg}^{-1}(\mathrm{n}=17)$, intravenously (IV) over $10 \mathrm{~min}$ to induce alaesthesia. Metocurine $0.42 \mathrm{mg} \cdot \mathrm{kg}^{-1}$ provided muscle relaxation. No further IV anaesthetic agenss were given. The haemodynamic response to induction, intubation, and surgen;, differed minimally between agents. The degree of rigidity on induction was identical with both agents, as were the intervals following induction at which patients lost consciousness, regained consciousness, or mel criteria for extubation. However. the interval until extubation criteria were met did correlate with the duraion of cardiopulmonary bypass. Sufentanil $15 \mu \mathrm{g} \cdot \mathrm{kg}^{-1}$, was clinically indistinguishable from fentanyl $100 \mu \mathrm{g} \cdot \mathrm{kg}^{-1}$, when used as the primary anaesthetic agent for coronary surgery.
\end{abstract}

\section{Key words}

ANALGESICS: fentanyl, sufentanil; ANAESTHETICS, INTRAVENOUS: fentanyl, sufentanil; ANAESTHESIA: cardiovascular; SURGERY: cardiovascular, cardiopulmonary bypass.

From the Department of Anesthesia, St. Boniface General Hospital, University of Manitoba, Winnipeg, Manitoba.

Address correspondence to: Dr. I.R. Thomson, Dept. of Anesthesia, St. Boniface General Hospital, 409 Taché Ave., Winnipeg, Manitoba, Canada R2H 2 A6.

Supported by the Medical Research Council of Canada, and Janssen Pharmaceutica.
Sufentanil is a synthetic opioid which is five to ten times as potent as fentanyl. ${ }^{1}$ The terminal elimination halftime of sufentanil in healthy humans is shorter than that reported for fentany! in a similar population. ${ }^{2,3}$ These properties suggest that sufentanil might be superior to fentanyl when used as the primary anaesthetic agent for cardiac surgery. Some investigators have compared fentanyl and sufentanil in patients undergoing cardiac surgery and report superior haemodynamic stability, 4,5 and shorter recovery times ${ }^{5}$ with sufentanil. Other investigators have emphasized the clinical similarities between these two opoids. ${ }^{6-8}$ We now report the findings of our own randomized double-blind comparison of fentanyl and sufentanil used as primary anaesthetic agents for coronary artery surgery.

\section{Methods}

Institutional approval was obtained from the Committee on Human Experimentation of the University of Manitoba. Informed consent was obtained from all participants. Patients undergoing elective coronary artery surgery whose resting left ventricular ejection fraction (EF) was 0.50 or greater were studied. Thirty-eight patients met the entry criteria and were randomly assigned to receive cither fentanyl $100 \mu \mathrm{g} \cdot \mathrm{kg}^{-1}(\mathrm{n}=20)$ or sufentanil $15 \mu \mathrm{g} \cdot \mathrm{kg}^{-1}$ $(\mathrm{n}=18)$ for induction. Premedication was morphine sulphate $0.1 \mathrm{mg} \cdot \mathrm{kg}^{-1} \mathrm{IM}$, and scopolamine $0.006 \mathrm{mg} \cdot \mathrm{kg}^{-1}$ IM, 60 min preoperatively. All preoperative antianginal medications were continued until the time of transfer to the operating room. In the operating room intravenous, intraarterial, and thermodilution pulmonary artery catheters were inserted with the aid of local anaesthetic infiltration. Following insertion of invasive monitoring devices the patients breathed 100 per cent oxygen from the anaesthetic circuit until a 5 min period of haemodynamic stability was noted. Metocurine iodide $0.06 \mathrm{mg} \cdot \mathrm{kg}^{-1} \mathrm{IV}$ was administered then in the hope of preventing muscle rigidity during induction. Anaesthesia was induced $2 \mathrm{~min}$ later by administering either fentanyl $10 \mu \mathrm{g} \cdot \mathrm{kg}^{-1} \cdot \mathrm{min}^{-1}$ IV, or sufentanil $1.5 \mu \mathrm{g} \cdot \mathrm{kg}^{-1} \cdot \mathrm{min}^{-1}$ IV for ten minutes. 
Narcotics were prepared in comparable dilutions by our Hospital Pharmacy and were delivered to the operating room in identical coded vials. Neither the attending anaesthetist nor the investigators had knowledge of which drug was being administered.

Throughout induction patients were addressed by their first name and repeatedly requested to open their eyes and take a deep breath. Failure to respond to both commands for $15 \mathrm{sec}$ was equated with loss of consciousness, and metocurine $0.36 \mathrm{mg} \cdot \mathrm{kg}^{-1} \mathrm{IV}$ was administered over the next $2 \mathrm{~min}$. The patients were manually ventilated by mask for the remainder of the 10 min narcotic infusion. The degree of muscle rigidity occurring during induction was graded according to the following criteria: (1) no rigidity, easily ventilated; (2) moderate rigidity, some ventilation possible; (3) severe rigidity, unable to ventilate. The end-tidal carbon dioxide tension was measured continuously and used to monitor ventilation. Tracheal intubation was accomplished upon termination of the narcotic infusion. The patients were then prepared, draped, and operated upon. Surgery was performed using hypothermic cardiopulmonary bypass with a bubble oxygenator, and arterial inflow filter. Adverse haemodynamic responses to induction, intubation, or surgery, were treated with vasoactive medications, or inhalational anaesthetic agents, at the discretion of the attending anaesthetist. No additional opioids, intravenous anaesthetics, or sedativehypnotic agents were administered.

Postoperatively, the patients were transferred to the Surgical Intensive Care Unit, where muscle relaxation was reversed shortly after arrival. Opioids and sedativehypnotics were withbeld. Mechanical ventilation was continued until the patients were awake and able to obey simple commands. Thereafter, their tidal volume (VT), vital capacity (VC), and inspiratory effort (IE), were assessed hourly. If the patients were haemodynamically stable and not bleeding actively, a trial of spontaneous ventilation via a "t-piece" was instituted when the following criteria were met: (1) VT $>5 \mathrm{ml} \cdot \mathrm{kg}^{-1}$; (2) VC> $10 \mathrm{ml} \cdot \mathrm{kg}^{-1}$; (3) IE $>-20 \mathrm{~cm} \mathrm{H}_{2} \mathrm{O}$; (4) oxygen saturation $>95$ per cent at an inspired oxygen fraction of 0.50 . The patients were considered to be ready for extubation if the following criteria were met after 30 min breathing 100 per cent oxygen via a "t-piece": (1) arterial oxygen saturation $>95$ per cent, and (2) $\mathrm{PaCO}_{2}<50$ torr. However, the patients were not necessarily extubated at that time. All patients were visited on the ward just before discharge and questioned about intraoperative awareness.

Complete haemodynamic profiles, including thermodilution cardiac output determinations in triplicate, were generated at the following times: (I) prior to induction, (2) after induction, (3) 1 min after intubation, (4) prior to incision, (5) $1 \mathrm{~min}$ after sternotomy, (6) $1 \mathrm{~min}$ after the
TABLE I Demographics (mean $\pm S D$ )

\begin{tabular}{lll}
\hline & $\begin{array}{l}\text { Fentanyl } \\
(n=16)\end{array}$ & $\begin{array}{l}\text { Sufentanil } \\
(n=17)\end{array}$ \\
\hline Age (years) & $57.0 \pm 8.1$ & $58.9 \pm 9.9$ \\
Ejection fraction & $0.66=0.11$ & $0.65 \pm 0.07$ \\
LVEDP (mmHg) & $14 \pm 7$ & $16 \pm 7$ \\
Weight (kg) & $85 \pm 3$ & $80 \pm 2$ \\
\# Grafts & $3.25 \pm 0.68$ & $3.18 \pm 1.01$ \\
Medications (n) & 16 & 16 \\
$\quad$ Nitrates & 12 & 13 \\
B-blocker & 12 & 13 \\
\hline
\end{tabular}

stemum was spread. Arterial blood for determination of serum fentanyl or sufentanil concentration was drawn at times $1,2,4$, and 6 , and also at the time of periaortic surgical dissection. The serum was separated and stored at $-20^{\circ} \mathrm{C}$ until the time of analysis by gas chromatography using a nitrogen-phosphorus detector. Our assay for fentanyl has been previously described, ${ }^{9}$ and is suitable for sufentanil as well. Arterial blood for determination of carbon dioxide tension $\left(\mathrm{PaCO}_{2}\right)$ was drawn prior to induction, 5 and $10 \mathrm{~min}$ following the start of induction, and $5 \mathrm{~min}$ after intubation, to verify the adequacy of ventilation. Because hypoventilation can be associated with sympathetic stimulation and hyperdynamic cardiovascular events, we established, prior to the study, criteria for exclusion of inadequately ventilated patients from subsequent analyses. Patients whose $\mathrm{PaCO}_{2}$ exceeded the preinduction value by greater than $5 \mathrm{mmHg}$ at any time during the study period were excluded.

Statistical analysis of haemodynamic variables and $\mathrm{PaCO}_{2}$ was made using analysis of variance (ANOVA) for repeated measures. Where analysis of variance revealed significant effects, the least squares means test was used to make appropriate intragroup and/or intergroup comparisons. Bonnferoni's correction was used to compensate for multiple comparisons. A p-value less than or equal to $0.05 / \mathrm{k}$ (where $\mathrm{k}$ equals the number of comparisons) was accepted as significant. Fischer's Exact Test, Student's t test, and the Wilcoxon Mann Whitney Rank Sums Test, were used where appropriate for intergroup statistical comparison of other variables. Regression analysis was used to seek correlations.

\section{Results}

Three patients who received fentanyl and one who received sufentanil were excluded from the study because of unacceptable increases in $\mathrm{PaCO}_{2}$. One additional patient given fentanyl was excluded because of marked agitation which developed when he became partially paralysed by the preinduction dose of metocurine. The remainder of 
this report is concerned with the remaining 16 patients who received fentanyl and the 17 who received sufentanil.

Demographic data from the two patient groups are shown in Table I. There were no significant differences between groups. Results of $\mathrm{PaCO}_{2}$ determinations are in Table Il. The groups did not differ with respect to $\mathrm{PaCO}_{2}$. There were slight but significant decreases in $\mathrm{PaCO}_{2}$ in both groups, but mean values remained within the normal range. Measured and derived haemodynamic variables are shown in Table III. The ANOVA revealed significant treatment-time interactions for mean arterial pressure (MAP), pulmonary capillary wedge pressure (PCWP), and pulmonary vascular resistance index (PVRI). Significant time-related effects were noted for all other variables. Differences between agents were minimal, and of doubtful clinical significance. Induction with fentanyl was associated with haemodynamic stability or slight stimulation. Heart rate (HR) increased slightly

TABLE II Arterial cabon dioxide tension (mean \pm SD)

\begin{tabular}{lllll}
\hline & Control & $\begin{array}{l}\text { Mid } \\
\text { induction }\end{array}$ & $\begin{array}{l}\text { End } \\
\text { induction }\end{array}$ & $\begin{array}{l}\text { I min Posr } \\
\text { intubation }\end{array}$ \\
\hline $\begin{array}{l}\text { Fentanyl } \\
n=16\end{array}$ & $44 \pm 6$ & $43 \pm 4^{*}$ & $42 \pm 4^{*}$ & $38 \pm 3^{*}$ \\
$\begin{array}{l}\text { Sufentanil } \\
n=17\end{array}$ & $44 \pm 5$ & $40 \pm 4$ & $41 \pm 4$ & $41 \pm 5^{*}$ \\
\hline
\end{tabular}

$* p<0.05 / 3$ vs control. with fentanyl, but not sufentanil, after induction and intubation. Induction with sufentanil was associated with haemodynarnic stability or slight depression. Mean arterial pressure and cardiac index declined after induction with sufentanil, but not fentanyl. Increases in systemic vascular resistance (SVRI) accompanied by decreases in cardiac index $(\mathrm{CI})$, were noted in both groups after sternotomy and sternal spread. The PVRI increased significantly after intubation, and sternal spread, in patients given fentanyl, and was significantly higher than comparable values in patients given sufentanil.

Table IV indicates the number of patients in each group in whom the attending anaesthetist intervened to treat untoward haemodynamic responses at various times during induction and surgery. Most haemodynamic abnormalities responded promptly to therapy, and the number of interventions required was relatively few. There were no differences between groups at any time, with respect to the number of interventions.

Serum fentanyl and sufentanil levels during the prebypass period are illustrated in Figure 1. The drug concentrations in the two groups declined in parallel. Serum sufentanil concentration fell from $5.4 \pm 0.4 \mathrm{ng} \cdot \mathrm{ml}^{-1}$ prior to incision, to $2.9 \pm 0.3 \mathrm{ng} \cdot \mathrm{ml}^{-1}$ at the time of periaortic surgical dissection. Comparable values in the patients given fentanyl were $29.5 \pm 2.8 \mathrm{ng} \cdot \mathrm{ml}^{-1}$ and $18.8 \pm 2.2 \mathrm{ng} \cdot \mathrm{ml}^{-1}$. There was no clear relationship

TABLE II] Haemodynamic variables

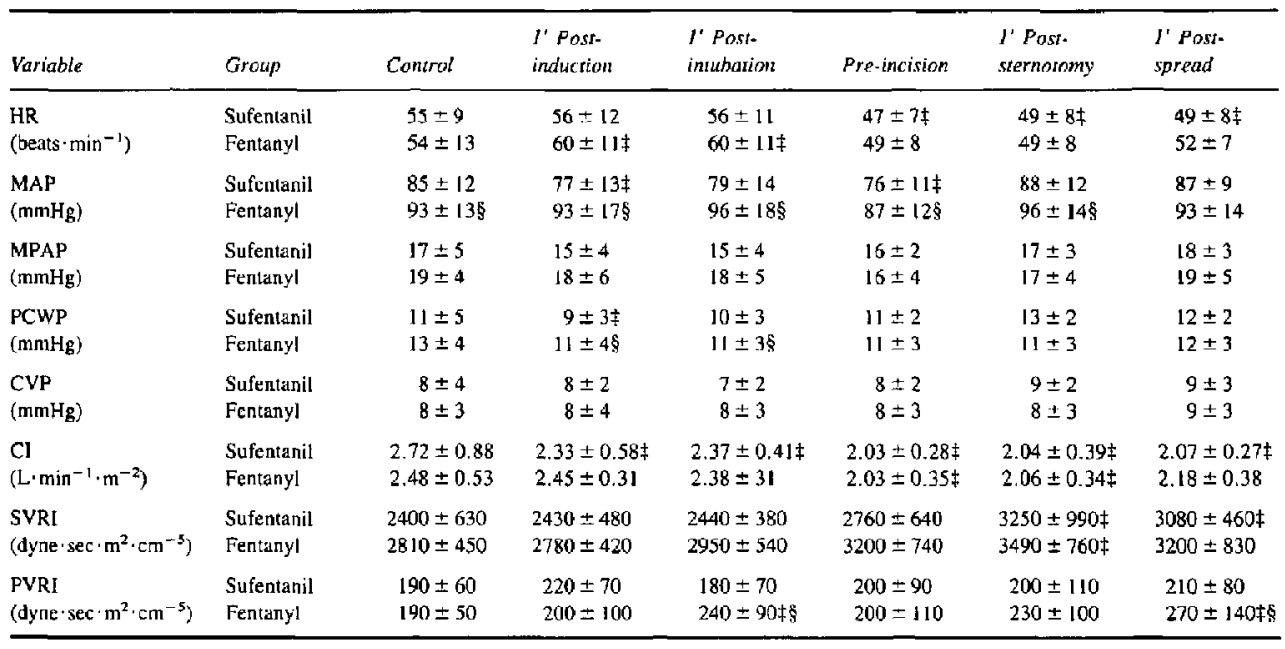

HR, heart rate. MAP, mcan arterial pressure. MPAP, mean pulmonary artery pressure. PCWP, pulmonary capillary wedge pressure. CVP, cenlral venous pressure. $\mathrm{Cl}$, cardiac index. SVRI, systemic vascular resistance index. PVRI, pulmonary vascular resistance index. $1 \mathrm{p}<0.05 / 5$ vs control.

$\S_{\mathrm{p}}<0.05 / 6$ between groups 
TABLE IV Number of interventions to treat hyperdynamic responses

\begin{tabular}{lllllll}
\hline & Induction & Intubation & Sternotomy & $\begin{array}{l}\text { Sternal } \\
\text { spread }\end{array}$ & $\begin{array}{l}\text { Aortic } \\
\text { dissection }\end{array}$ & Pastbypass \\
\hline Sufentanil & 1 & 0 & 0 & 1 & 2 & 7 \\
Fentanyl & 3 & 1 & 0 & 1 & 1 & 6 \\
\hline
\end{tabular}

TABLE $V$ Incidence of rigidity

\begin{tabular}{llll}
\hline & \multicolumn{2}{l}{ Severity of rigidity* } \\
\cline { 2 - 4 } & 1 & 2 & 3 \\
\hline Sufentanil & 7 & 6 & 4 \\
Fentanyl & $\mathbf{8}$ & 6 & 2 \\
\hline
\end{tabular}

* See text for criteria.

between serum opioid concentrations and the occurrence of hyperdynamic responses to surgery.

The two opioids did not differ with respect to the degree of rigidity encountered during induction (Table v). Neither did they differ with respect to the intervals after induction at which criteria for loss of consciousness, awakening, and extubation, were met (Table VI). Data regarding awakening, and fitness for extubation, were based on 25 patients, 13 of whom received sufentanil and 12 fentanyl. We excluded two patients who were sedated because of agitation on awakening, two who reccived additional narcotic during reoperation for

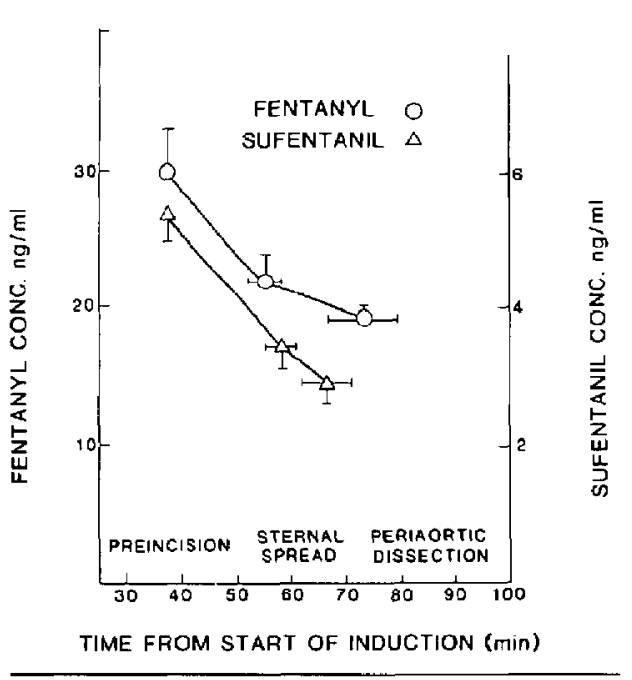

FIGURE 1 Serum fentanyl and sufentanil concentrations (mean \pm SEM) during the period prior to cardiopulmonary bypass. haemorrhage, two who had neurological complications preventing assessment, and two who required prolonged ventilatory support because of respiratory failure. Regression analysis revealed a positive correlation between the duration of cardiopulmonary bypass and the interval from induction to fulfilment of criteria for extubation (Figure 2)

One patient who received sufentanil recalled being unable to move during the skin preparation for surgery. One patient given fentanyl recalled being defibrillated at the end of bypass. Neither patient was distressed about experiencing recall, and neither remembered any other intraoperative events.

\section{Discussion}

Sufentanil is significantly more potent than fentanyl, and has a shorter half-time of elimination in normal subjects) ${ }^{1-3}$ However, there is little evidence to support the hypothesis that these two properties impart any particular advantage to sufentanil, compared with fentanyl, when used in anaesthetic doses as the primary agent for cardiac surgery. ${ }^{4-8}$ Using a randomized but not double-blind $\mathrm{ex}$ perimental design, De Lange et al, ${ }^{4}$ compared fentanyl $122 \pm 15 \mu \mathrm{g} \cdot \mathrm{kg}^{-1}$, with sufentanil $12.9 \pm 0.5 \mu \mathrm{g} \cdot \mathrm{kg}^{-1}$, in 37 patients undergoing coronary artery bypass grafting. They noted superior haemodynamic stability with sufentanil at the time of stemotomy. However, they noted no difference between the two agents with respect to recovery times, or in the time until patients were ready for extubation. In another randomized but not double-blind experiment, Howie et al. ${ }^{6}$ compared fentanyl $100 \mu \mathrm{g} \mathrm{kg}^{-1}$, with sufentanil $20 \mu \mathrm{g} \cdot \mathrm{kg}^{-1}$, in 48 patients undergoing cotonary artery bypass grafting. They noted minimal

TABLE VI Elapsed time from start of induction (mean $\pm S D$ )

\begin{tabular}{lcr}
\hline & $\begin{array}{l}\text { Sufentanil } \\
(n=17)\end{array}$ & \multicolumn{1}{c}{$\begin{array}{l}\text { Fentanyl } \\
(n=16)\end{array}$} \\
\hline Loss of consciousness $(\mathrm{min})$ & $1.78 \pm 0.33$ & $1.83 \pm 0.37$ \\
Start of bypass $(\mathrm{h})$ & $1.61 \pm 0.36$ & $1.78 \pm 0.48$ \\
End of bypass(h) & $3.90 \pm 0.86$ & $4.00 \pm 0.81$ \\
Arrival in SICU (h) & $\mathbf{5 . 5 7 \pm 1 . 2 7}$ & $5.34 \pm 0.88$ \\
Awake in SlCU (h)* & $\mathbf{8 . 1 1} \pm 2.48$ & $\mathbf{7 . 4 2 \pm 2 . 1 5}$ \\
Met extubation criteria $(\mathrm{h})^{*}$ & $17.31 \pm 3.59$ & $19.96 \pm 5.00$ \\
\hline
\end{tabular}

SICU, Surgical Intensive Care Unit.

*Based on $\mathrm{a}=25$ (see text). 


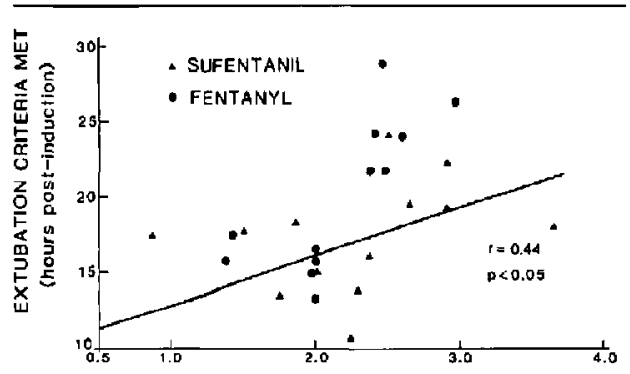

DURATION OI BYPASS (hOU)

FIGURE 2 The relationship between the duration of cardiopulmonary bypass and the interval between induction and fulfilment of extubation criteria.

haemodynamic differences between agents, alıhough HR was lower at stemotomy with fentanyl. Postoperatively, there was no difference between agents in the recovery times or time to extubation. In a randomized trial, Sanford et al..$^{5}$ compared fentanyl $95.4 \pm 9.9 \mu \mathrm{g} \cdot \mathrm{kg}^{-1}$, with sufentanil $18.9 \pm 2.2 \mu \mathrm{g} \cdot \mathrm{kg}^{-1}$, in 18 patients undergoing cardiac surgery. They reported that postoperative recovery times, and the time to extubation, were significantly shorter with sufentanil. Two other studies, published in abstract, comment on the similarity in haemodynamics, ${ }^{7,8}$ hormonal responses, and recovery times, ${ }^{7}$ with these two opioids.

We feel that our experimental design was sound, and effectively eliminated investigator bias. Our study was conducted according to a strictly randomized doubleblind protocol, and our findings strongly support the majority opinion that when used as the primary agent for coronary artery surgery, similarities between sufentanil and fentanyl are remarkable and differences are minimal.

The relative potency of sufentanil to fentanyl in humans is not known, but a ratio of 5-10:1 is generally accepted.' The dose ratio of 6.5:1 for fentanyl to sufentanil used by us is within this range. The resulting ratios of serum fentanyl to sufentanil concentration approximated 6.5:1 during the precardiopulmonary bypass period. Mean serum fentanyl concentrations in the range of $19-30 \mathrm{ng} \cdot \mathrm{ml}^{-1}$, and sufentanil cuncentrations between 3.0 and $5.5 \mathrm{ng} \cdot \mathrm{ml}^{-1}$ during the prebypass period, resulted in similar haemodynamics, comparable depth of anaesthesia, and the same incidence of recall. These concentrations correspond to those reported by others as producing haemodynamic stability in the majority of patients. ${ }^{7,10}$

Our study clearly demonstrates no differences in the time to loss of consciousness when clinically equipotent doses of these two opioids are administered in a strictly double-blind fashion. Similarly, the severity of rigidity caused by the two agents does not differ when they are administered in this manner. The more rapid onset of loss of consciousness with sufentanil reported by others ${ }^{4-6}$ is likely artifactual and related to more rapid administration of sufentanil or to investigator bias.

The time required for patients to regain consciousness and fulfil criteria for extubation did not differ between agents. Patients were ready for extubation $17.3 \pm 3.6 \mathrm{hr}$ and $20.0 \pm 5.0 \mathrm{hr}$ after induction, with sufentanil and fentanyl respectively. The trend to earlier fulfilment of extubation criteria with sufentanil might have reached statistical significance in a larger study. However, we feel that the 2.7 hour difference between treatment groups noted in our study is clearly not clinically significant, as neither anaesthetic regimen appeared suitable for "early" postoperative extubation. If we consider a six-hour difference in time to fulfilment of extubation criteria as "clinically significant," then power analysis indicates that we had an 80 per cent probability of detecting this based on data from 25 patients. Our findings agree with those of most investigators, ${ }^{4,6,7}$ but are substantially at variance with those of Sanford et al. ${ }^{5}$ who reported extubation $22.1 \mathrm{hr}$ and $14.8 \mathrm{hr}$ after induction with fentanyl $95.4 \mu \mathrm{g} \cdot \mathrm{kg}^{-1}$ and sufentanil $18.9 \mu \mathrm{g} \cdot \mathrm{kg}^{-1}$ respectively. Sanford et al. administered the drugs according to subjective electroencephalographic criteria, and the investigators knew which agent they were using. Thus, investigator bias might have influenced the timing of drug administration. In addition, the treatment groups involved were not identical. Three of nine patients in Sanford's sufentanil group underwent aortic valve replacement, whereas all other patients had coronary artery bypass grafting. These authors also reported more postoperative "haemodynamic instability," causing delayed extubation, in patients given fentanyl. This phenomenon bas not been noted by others. Sanford et al. attributed this to an intrinsic difference between the two opioids, but an alternative interpretation is that this unusual result indicates that the two groups of patients were not comparable.

The question arises as to why pharmacokinetic differences between fentanyl and sufentanil in normal subjects are not reflected in significantly different recovery times after coronary artery bypass grafting procedures. An obvious explanation is that kinetics determined by administration of low doses of opioids to normal subjects undergoing minor surgery are not applicable to highdose opioid anaesthesia in older patients with candiovascular disease. For example, in a study of ten patients undergoing abdominal aortic surgery, we found that the terminal half-time of elimination for fentanyl was nearly twice that reported in healthy subjects. ${ }^{9}$ The pharmacokinetics of these opioids, when used in cardiac surgery, are not known, and are unlikely to be determined accu- 
rately, because of the profound derangements in physiology introduced by cardiopulmonary bypass. ${ }^{11}$ Another hypothesis, which is supported by our findings, is that pharmacokinetic differences between agents are obscured by other factors. For example, the severity of neurological dysfunction after cardiac surgery has been correlated with the duration of cardiopulmonary bypass. ${ }^{12}$ We retrospectively examined the hypothesis that respiratory depression postoperatively is a manifestation of diffuse brain injury caused by cardiopulmonary bypass. We noted a positive correlation between the interval from induction until extubation criteria were fulfilled, and the duration of cardiopulmonary bypass. This correlation explains a relatively small proportion of the variability in recovery times and in no way proves causality. However, it is compatible with our general hypothesis regarding the importance of factors other than pharmacokinetics in determining recovery time after cardiac surgery.

In conclusion, in this randomized double-blind comparison, fentanyl $100 \mu \mathrm{g} \cdot \mathrm{kg}^{-1}$ was clinically indistinguishable from sufentanil $15 \mu \mathrm{g} \cdot \mathrm{kg}^{-1}$, when used as the primary anaesthetic agent for coronary artery surgery.

\section{Acknowledgments}

We thank the surgeons, Drs. J. Barwinsky, S.K. Bhattacharya, M. Cohen, S.W. Kim, J. Teskey, and K. Warrian, and the cardiac anaesthetists, Drs, L.G. Brownell, J.D. Culligan, R.M. Friesen, D. Peters, and J.S. Scatliff, whose unstinting patience and cooperation was essential to our efforts. Janice Chalmers RT, performed the narcotic assays, and Mary Cheang was our statistical consultant. Janssen Pharmaceutica generously provided sufentanil, and the alfentanil used in the internal standard.

\section{References}

1 Bovill JG, Sebet PS. Stanley TH. Opioid analgesics in anesthesia: with special reference to their use in cardiovascular anesthesia. Anesthesiology 1984; 61: 731-55.

2 Bovill JG, Sebel PS, Blackburn CL, Oei-Lim V, Heykants JI. The pharmacokinetics of sufentanil in surgical patients. Anesthesiology 1984; 61: 502-6.

$3 \mathrm{McLain} D A, H u g C C$. Intravenous fentanyl kinetics. Clin Pharmacol Ther $1980 ; 28: 106-14$.

4 De Lange S, Boscoe MJ, Stanley TH, Pace N. Comparison of sufentanil $\mathrm{O}_{2}$ and fentanyl- $\mathrm{O}_{2}$ for coronary artery surgery. Anesthesiology 1982; 56:112-8.

5 Sanford $T J$ Jr, Smith NT, Dec-Silver $H$, Harrison WK. A comparison of morphine, fentanyl, and sufentanil anesthesia for cardiac surgery: induction, emergence, and extubation. Anesth Analg 1986; 65: 259-66.
6 Howie MB, McSweeney TD, Lingam RP, Maschke SP. A comparison of fentanyl- $\mathrm{O}_{2}$ and sufentanil $-\mathrm{O}_{2}$ for cardiac anesthesia. Anesth Analg 1985; 64: 877-87.

7 Murkin $I M$, Moldenhauer CC, Griesemer RW, Hug CC. Fentanyl vs sufentanil: comparison of hemodynamic and catecholamine responses during coronary artery (CABG) surgery. Anesthesiology 1984; 61: A375.

8 Rosow CE, Philbin DM, Moss J, Keegan MA, Schneider $R C$. Sufentanil vs fentanyl: I. Suppression of hemodynamic responses. Anesthesiology 1983; 59: A323.

9 Hudson R.J. Thomson IR, Cannon JE, Friesen RM, Measherall RC. Pharmacokinetics of fentanyl in patients undergoing abdominal aortic surgery. Anesthesiology 1986 ; 64: 334-8.

10 Wynands JE, Wong P. Townsend GE, Sprigge JS, Whalley $D G$. Narcotic requirements for intravenous anesthesia. Anesth Analg 1984; 63: 101-5.

11 Koska AJ. Romagnoli A, Kramer WG. Effect of cardiopulmonary bypass on fentanyl distribution and elimination Clin Pharmacol Ther 1981; 29: 100-5.

12 Soraniemi KA, Juolasmaa MA, Hokkanen ET. Neuropsychologic outcome after open-heart surgery. Arch Neurol $1981 ; 38: 2-8$.

\section{Résumé}

Utilisant un protocole randomisé à double insu les auseurs on comparé deux régimes d" anesthésie au narcotic chez 33 patients ayant une bone fonction ventriculaire et devam subir une chirurgie coronarienne. Après prémédication avec de la morphine et scopolamine, les patients ont reçu soit du fentanyl $100 \mu \mathrm{g} \cdot \mathrm{kg}^{-i}(\mathrm{n}=16)$ ou du sufentanil $15 \mu \mathrm{g} \cdot \mathrm{kg}^{-1}(\mathrm{n}=17)$. par voie intraveineuse en dix mintues afin d'induire l'anesthésie. La mérocurine $0.42 \mathrm{mg} \cdot \mathrm{kg}^{-1}$ fur administrée pour relâchement musculaire. Aucune autre injection intraveineuse d'agent anesthésique ne fut donnée. La réponse hémodynamique à l'induction, intubation et chirurgie a démontré une différence minime entre les deux agents. Le degré de rigidité d l'induction etait identique avec les deux agenss. Il en fut de même pour les temps de perte de conscience, regain de conscierce ou les criteres d'axtubation. Cependant l'intervalle pour anteindre les critères requis de l'extubation étaicnt en corrélation avec la durée de la CEC. Le sufentanil $15 \mu \mathrm{g} \cdot \mathrm{kg}^{-1}$ n'étaient pas cliniquement différent du fentanyl $100 \mu \mathrm{g} \cdot \mathrm{kg}^{-1}$ lorsqu'utilise comme seul agent anesthésique pour la chirurgie coronarienne. 